\title{
PROPOSTA SIMPLES PARA O EXPERIMENTO DE ESPALHAMENTO RAYLEIGH
}

\author{
Adriano José Ortiz ${ }^{1}$ \\ Licenciando em Física Londrina - PR \\ Carlos Eduardo Laburú2 \\ Osmar Henrique Moura da Silva \\ Departamento de Física - UEL \\ Londrina - PR
}

\section{Resumo}

Este trabalho traz uma proposta alternativa para o experimento de espalhamento Rayleigh apresentado e discutido em Krapas e Santos (2002), neste periódico. Além de ser mais simples e de baixo custo, a proposta aqui sugerida propõe também demonstrar experimentalmente outros fenômenos físicos como a polarização da luz do céu, do arco-íris e a reflexão polarizada em superfícies não condutoras, assim como determinar a direção dessas polarizações. A polarização será observada com a ajuda de polaroides obtidos de mostradores de cristais líquidos tirados de equipamentos eletrônicos danificados e a direção de polarização dos polaroides será estabelecida pela observação do ângulo de Brewster no experimento de reflexão.

Palavras-chave: Experimento; Física; Rayleigh; baixo custo.

\footnotetext{
+ A simple proposal for Rayleigh's scaterring experiment

* Recebido: fevereiro de 2010. Aceito: julho de 2010.

${ }^{1}$ Bolsista PIBIC - CNPq.

${ }^{2}$ Apoio parcial CNPq, Fundação Araucária e FAEPE/UEL.
} 


\begin{abstract}
This work presents an alternative proposal for Rayleigh's scattering experiment presented and discussed in Krapas and Santos (2002) in this journal. Besides being simple and low-cost, the proposal suggested here is also proposing to demonstrate experimentally other physical phenomena such as polarization of light from the sky, the rainbow and reflection on non-conductive surfaces, as well as determine the direction of these biases. The polarization will be observed with the aid of Polaroid obtained from liquid crystal displays taken from damaged electronic devices and the Polaroid polarization direction will be established by the observation of Brewester's angle in reflection experiment.
\end{abstract}

Keywords: Experiment; Physics; Rayleigh; low-cost.

\title{
I. Introdução
}

Em Krapas e Santos (2002), o modelo de espalhamento Rayleigh da luz foi empregado para acomodar a estratégia didática de modelagem no ensino de ciências. No que diz respeito à parte experimental, o trabalho traz uma explicação teórica desse fenômeno e, em seguida, sugere um experimento que pode ser realizado em ambiente escolar ou em eventos científicos. O intuito do experimento é simular o fenômeno físico que faz com que vejamos o céu azul durante o dia e o pôr-do-sol avermelhado.

No entanto, ao seguirmos a indicação de rodapé da página 346 do trabalho de Krapas \& Santos (2002), não conseguimos reproduzir o efeito desejado. Em virtude também da relativa dificuldade de obtenção do material indicado e da periculosidade envolvida com a solução de ácido sulfúrico a ser manipulada por estudantes de nível médio, apresentamos uma alternativa experimental mais simples, sem o mencionado perigo, e que não gera maiores dificuldades na realização experimental, que foi originalmente sugerida em Crawford Jr. (1974). Além disso, pretendemos estender e complementar o trabalho de Krapas \& Santos (2002), propondo experimentos que usam polarizadores para mostrar que o espalhamento Rayleigh da luz é polarizado, sendo, por consequência, polarizada a luz do céu, dependendo da direção em que se olha, assim como o é a luz vinda de arco-íris e da reflexão de superfícies não-condutoras. 
O objetivo deste trabalho restringe-se à parte experimental e não tem intenção de aprofundar a parte teórica, que pode ser encontrada em livros didáticos ou no filme do MIT da aula de Walter Lewin, citados nas referências.

\section{Experimento Alternativo de Espalhamento Rayleigh da luz}

O experimento sugerido em Crawford Jr. (1974, p. 404) propõe simplesmente pingar por volta de duas a quatro gotas de leite em um litro de água, num vasilhame transparente, como em um béquer, por exemplo. De forma semelhante à solução química proposta em Krapas \& Santos (2002), as partículas de leite dissolvidas espalham a luz de uma lanterna colocada perpendicularmente à direção de observação (Fig. 1). Para ver com maior clareza o fenômeno, inclusive a polarização, a melhor condição experimental é aquela em que podemos notar um feixe cilíndrico de luz passando através do líquido.

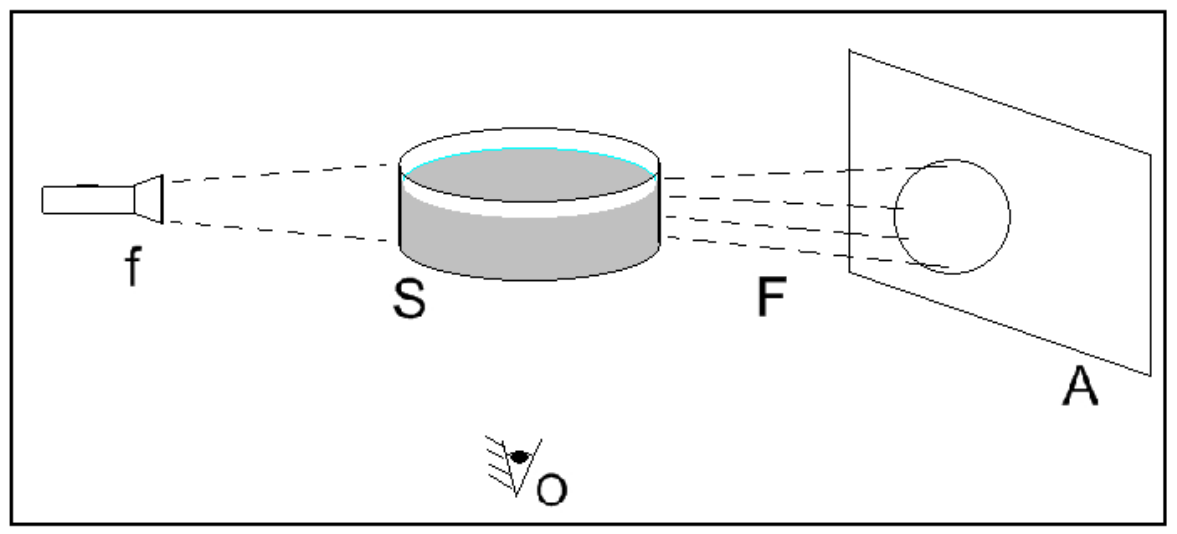

Fig. 1 - $f$ : lanterna; S: substância contendo água e gotas de leite; F: feixe de luz; A: anteparo; O: observador da luz polarizada da substância vista em posição perpendicular à propagação da luz lanterna-anteparo.

Porém, é preciso advertir que, apesar de o experimento simular o espalhamento da luz azul, esse efeito não é observado diretamente, pois a luz espalhada, vista pelo observador $(\mathrm{O})$ da Fig. 1, não se diferencia muito do branco. Contudo, a conclusão de que a luz azul é espalhada, pode ser constatada indiretamente quando se olha a luz refletida num anteparo branco colocado após o vasilhame 
(Fig. 2), ou observando diretamente o feixe de luz da lanterna que sai através do vasilhame.

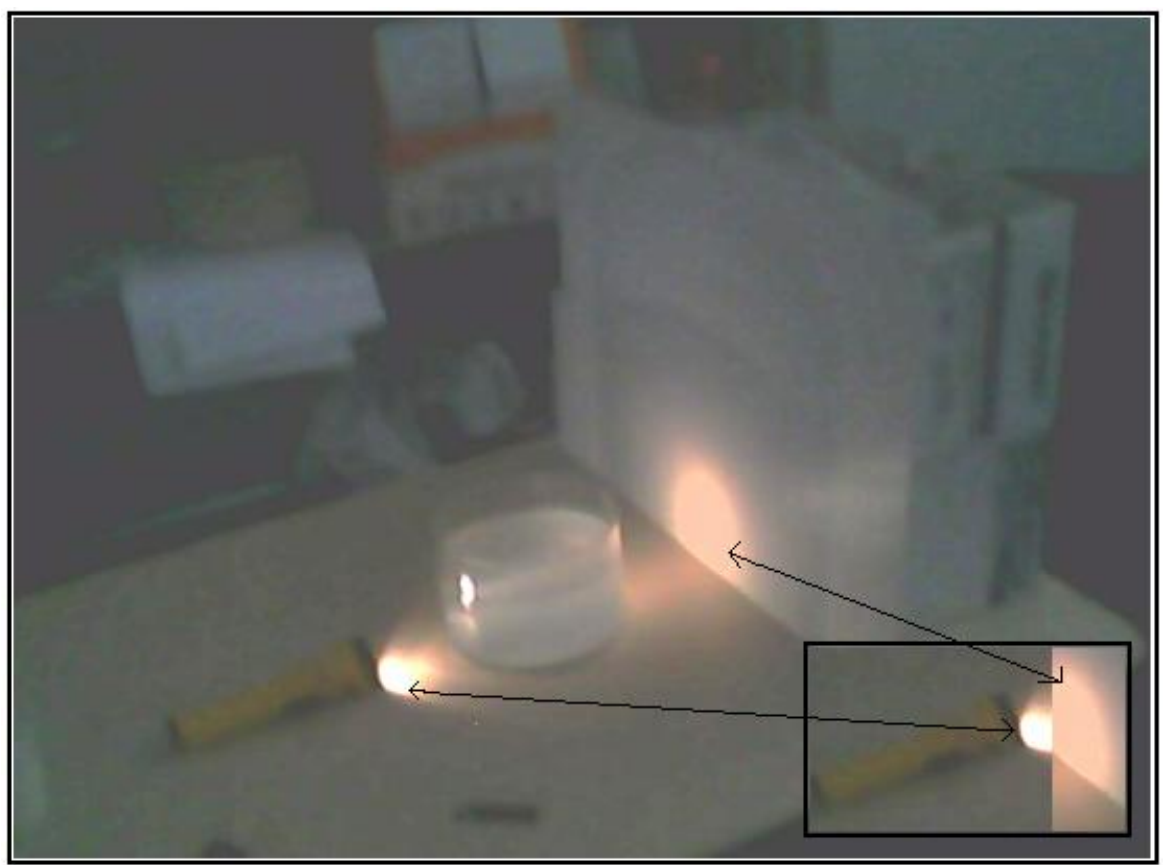

Fig. 2 - A luz que sai diretamente da lanterna tem um tom branco, enquanto a luz refletida no anteparo é avermelhada. Isso pode ser melhor visto pela justaposição dessas cores montada num pequeno quadro em canto inferior direito desta figura.

Em ambos os casos, vê-se que a luz está bem mais avermelhada do que a que sai imediatamente do filamento da lanterna, fenômeno semelhante ao que acontece quando se olha o crepúsculo. Isso indica que os comprimentos de onda maiores não sofrem desvio e que essa cor mais amarelada ou avermelhada é devido à perda no feixe de luz das cores com menores comprimentos de onda, como o azul, devido ao espalhamento proporcionado pelas partículas em suspensão no fluido. 


\section{Polarização por Espalhamento Rayleigh}

O fenômeno de polarização da luz permite entendê-la como uma onda transversal. A luz normalmente não é polarizada, ou seja, os vetores campo elétrico e campo magnético apontam em todas as direções perpendiculares à propagação da onda. Entretanto, ao refletir ou passar através de algumas superfícies, devido à organização molecular das mesmas, apenas alguns componentes desses campos com determinada direção são mantidos. A onda formada por esses componentes é denominada polarizada.

Outra forma de polarizar uma onda eletromagnética é a partir do fenômeno de espalhamento. No espalhamento, uma radiação que incide sobre um núcleo espalhador e não interage com ele é totalmente transmitida, entretanto, a radiação absorvida por esse núcleo é, dependendo do ângulo, irradiada novamente na forma polarizada. Isso ocorre no espalhamento Rayleigh da luz. Dessa forma, além da cor azulada, dependendo da direção que observamos a luz do céu ela é também parcialmente ou totalmente polarizada. Essa polarização por espalhamento Rayleigh vem da interação entre o campo elétrico da onda e as moléculas das partículas espalhadoras. $\mathrm{O}$ campo elétrico homogêneo gerado pela radiação incidente produz um momento de dipolo induzido sobre as partículas. Esse dipolo elétrico, então, oscila em uma direção fixa e produz uma onda eletromagnética plana, que será a onda espalhada.

Para analisarmos a direção de espalhamento dessa onda, consideremos o comportamento da nossa partícula enquanto dipolo elétrico. Semelhante a uma antena, essa partícula irá irradiar a componente com intensidade máxima do campo eletromagnético na direção perpendicular ao seu eixo de observação e de propagação original e terá a outra componente nula (Fig. 3). Assim, podemos notar que, quando observamos a luz solar refletida a partir de uma direção perpendicular a sua direção de propagação vinda do Sol, essa luz chega para nós na forma polarizada.

Em nosso experimento, esse fenômeno é constatado bastando que olhemos na direção lateral do béquer, perpendicularmente à direção de propagação da luz da lanterna, através de um polaroide.

Para realizar a observação acima, assim como as demais que se seguirão, é necessário conseguir um polaroide. Em Laburú et al (1998), é indicada uma maneira de se obterem, facilmente e sem nenhum custo, polaroides de mostradores de cristais líquidos. 


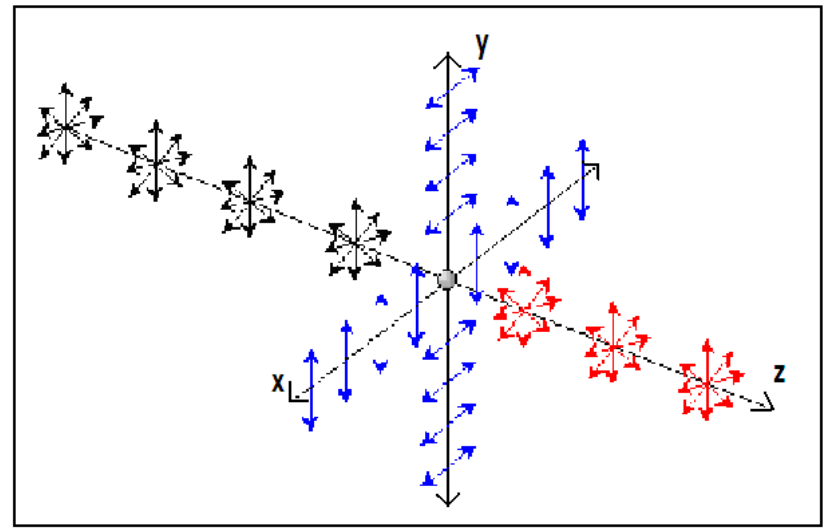

Fig. 3 - Polarização por espalhamento.

\section{Determinação da direção de polarização}

Estando de posse de um polaroide outro problema é achar a sua direção de polarização. Para isso, fazemos incidir um raio de luz não polarizado de uma lanterna sobre a superfície de um pedaço de vidro plano e observamos a luz refletida. Para o caso do vidro, o ângulo que ocorre polarização total é de 560 em relação à normal e a direção da polarização da onda que estamos a observar é paralela à superfície refletora e logicamente perpendicular à direção de propagação (Fig. 4).

O ângulo acima é denominado de ângulo de Brewster e podemos usá-lo para determinar de forma simples a direção de polarização dos polaroides, além de também poder verificar que a luz refletida em superfícies não-condutoras, diferentemente das condutoras, sofre o fenômeno de polarização. Assim, ao olharmos a luz refletida pelo vidro através de uma chapa polaroide ao mesmo tempo em que o giramos vai haver uma posição do polaroide que a intensidade da luz será mínima. Para essa posição com observação de luz mínima, a direção vertical na chapa determina a direção de polarização da mesma e, caso rodemos o polaroide mais $90^{\circ}$, essa direção deixará passar a intensidade de luz máxima. Nessa última posição, a direção de polarização do polaroide será paralela à direção de polarização da luz.

Tendo estabelecida a direção da chapa polaroide pela técnica do ângulo de Brewster, podemos usá-la em seguida para observar a direção da luz polarizada do espalhamento de Rayleigh tanto no experimento sugerido com leite como para observar a luz azul do céu. Em ambos os casos, pode-se ver que a luz espalhada, perpendicular à direção do feixe de propagação da lanterna ou do Sol, tem direção 
vertical de polarização, pois sua maior intensidade luminosa ocorre quando a direção da chapa polaroide tem essa direção.

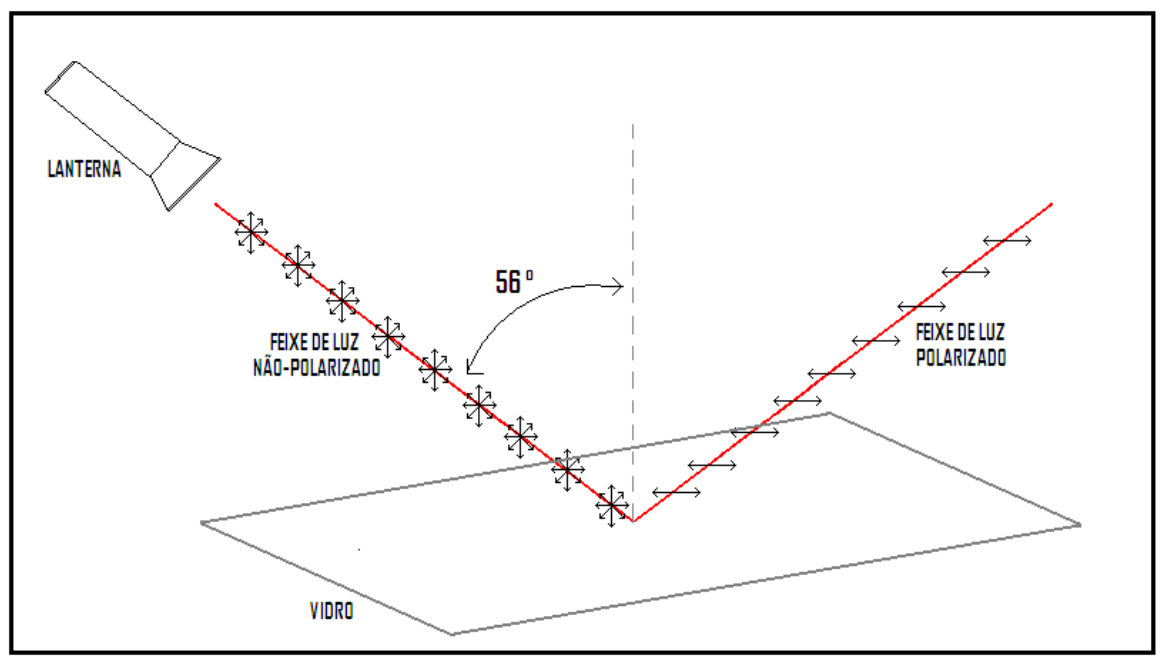

Fig. 4 - Direção de polarização por reflexão numa superfície não condutora. Observar que essa direção é paralela à superficie do vidro.

\section{Observando a luz polarizada do arco íris}

Com o polaroide também podemos constatar que o arco-íris é polarizado e que a direção de polarização é tangente ao semicírculo do arco (Fig. 5). 


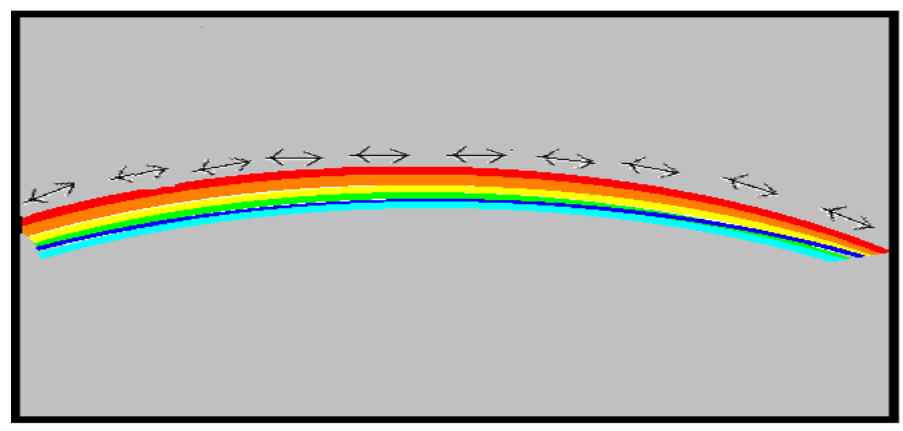

Fig. 5 - Direção de polarização do arco-íris.

A razão para a polarização do arco-íris se deve ao fato de que as reflexões internas que ocorrem dentro das gotas de água que formam o arco-íris se dão simplesmente muito próximas ao ângulo de Brewster. Para demonstrar isso em laboratório, podemos simular um arco-íris e comprovar a direção de polarização com a chapa de polaroide, contendo sua direção de polarização estabelecida, com o seguinte experimento muito simples sugerido em Electricity and Magnetism (2002), conforme a Fig. 6.

Para este experimento, necessita-se de uma fonte de luz não polarizada (f), um colimador que, no caso, utilizamos duas placas brancas, que podem ser construídas com papel sulfite colado sobre uma placa de madeira ou outro material (c), um balão volumétrico contendo água (R) e um polaroide (p) (ver Fig. 6). Ao abastecer o balão volumétrico com água e direcionar a fonte de luz passando pela fenda sobre ele, para um determinado ângulo será possível observar o arco-íris refletido nas placas brancas do mesmo lado que se encontra o balão. Então, basta segurar um polaroide, com a direção de polarização já conhecida entre o balão e a imagem do arco-íris e girá-lo, buscando a direção que a intensidade da imagem na placa desaparece ou torna-se mínima. Como já dissemos anteriormente, nesse caso a direção de polarização da luz será perpendicular à direção de polarização do polaroide. 


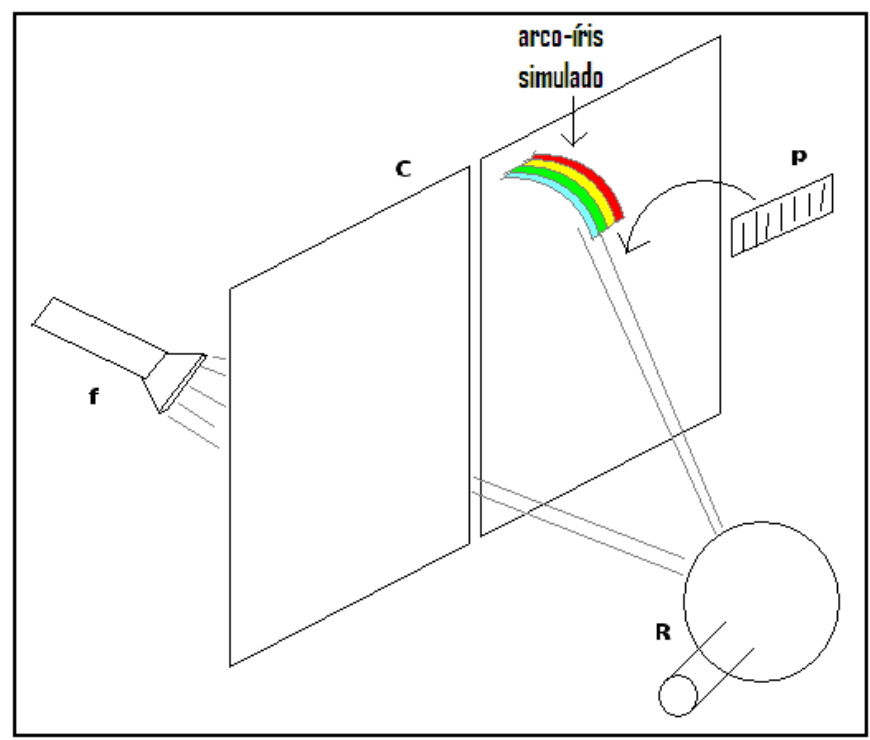

Fig. 6-Experimento que simula um arco-íris.

\section{Conclusões}

Este trabalho pretendeu apresentar uma opção mais simples e segura para o experimento de espalhamento Rayleigh sugerido em Krapas e Santos (2002), além de propor novos experimentos muito fáceis de serem realizados pelos alunos do ensino básico e que complementam o fenômeno ligado à produção da luz azul do céu.

\section{Bibliografia}

CRAWFORD Jr., F. S. Ondas, Berkley Physics Course. España: Editorial Reverté S.A., 1974. v. 3.

KRAPAS, S.; SANTOS, P. A. M. Modelagem do espalhamento Rayleigh da luz com propósitos de ensino e aprendizagem. Caderno Brasileiro de Ensino de Física, v. 19, n. 3, p. 341-350, 2002.

LABURÚ, C. E.; SIMÕES, M.; URBANO, A. Mexendo com polaroides e mostradores de cristais líquidos (o ensino da Física contemporânea, tendo como pano de 
fundo a Física do cotidiano). Caderno Catarinense de Ensino de Física, v. 15, n. 2, p. 192-205, 1998.

HALliDAY, D.; RESNICK, R.; WALKER, J. Óptica e Física Moderna, Fundamentos de Física. 4. ed. Rio de Janeiro: LTC Editora, 1995. v. 4.

ELECTRICITY AND MAGNETISM. Walter Lewin, Spring 2002 Lecture 30, 31. Disponível em: < http://web.mit.edu/smcs/8.02/>. 